\title{
Double-Outlet Left Ventricle with L-Malposition of the Great Arteries and Subpulmonary Ventricular Septal Defect
}

\author{
Carolina Putotto · Marta Unolt · Dario Marino
}

Received: 10 April 2013/Accepted: 7 May 2013/Published online: 21 May 2013

(C) Springer Science+Business Media New York 2013

In a recent issue of your journal we read the interesting report on an infant with "Double-outlet left ventricle with L-malposition of the great arteries and subpulmonary ventricular septal defect" [6].

The authors suggested that "this anatomic variation has not been described to date in patients with a double outlet left ventricle", this may be indeed a rare finding, however, it has been reported in the literature in at least three occasions in children with double outlet left ventricle [2-4].

In subjects with double outlet left ventricle the L-position of the aorta (i.e. the aorta anterior and left sided) is a well known anatomic pattern in which the ventricular septal defect is usually in subaortic position $[1,5]$. However in some rare cases of double outlet left ventricle, the Lposition of the aorta can be associated with a subpulmonary ventricular septal defect as clearly showed by two-dimensional echocardiography in the present paper [6] and in the previous reports since 1992 [2,3].

\section{References}

1. Bharati S, Lev M, Stewart R, McAllister HA Jr, Kirklin JW (1978) The morphologic spectrum of double outlet left ventricle and its surgical significance. Circulation 58(3 Pt 1):558-565

2. Kiliç A, Saraçlar M, Ozkutlu S (1999) Double outlet left ventricle with subpulmonary ventricular septal defect and pulmonary hypertension. Cardiol Young 9(6):624-626

3. Marino B, Bevilacqua M (1992) Double-outlet left ventricle: twodimensional echocardiographic diagnosis. Am Heart J 123(4 Pt 1):1075-1077

4. Pacifico AD, Kirklin JW, Bargeron LM Jr, Soto B (1973) Surgical treatment of double-outlet left ventricle. Report of four cases. Circulation 48(1 Suppl):III19-III23

5. Van Praagh R, Weinberg P, Srebro JP (1989) Double-outlet left ventricle. In: Adams F, Emmanouilides G, Riemenschneider J (eds) Moss' heart disease in infants, children, and adolescents, 4th edn. Williams \& Wilkins, Baltimore, pp 461-485

6. Vukomanovic V, Prijic S, Bjelakovic B (2013) Double-outlet left ventricle with L-malposition of the great arteries and subpulmonary ventricular septal defect. Pediatr Cardiol 34:476-477
C. Putotto $(\bowtie) \cdot$ M. Unolt $\cdot$ D. Marino

Department of Pediatrics, "Sapienza" University, Viale Regina

Elena, 324, 00161 Rome, Italy

e-mail: caro_85@hotmail.it 